\title{
La racionalidad del creyente: la propuesta filosófica (y teológica) analítica de Roger Pouivet*
}

\author{
ALEJANDRO PÉREZ \\ Institut Jean-Nicod (CNRS-EHESS-ENS), Paris \\ alejotou@gmail.com
}

Roger Pouivet (R. P.) profesor de la Université de Lorraine y director del centro de investigación Archives Poincaré, es uno de los principales representantes de la filosofía analítica de la religión en Francia (y en el mundo anglosajón). En su nuevo libro sobre las creencias religiosas, R. P. se propone de defender la siguiente tesis: "la creencia cristiana en la existencia de Dios es una creencia cuya legitimidad epistemológica está garantizada” [p. 9]. Ahora bien, la pregunta que se plantea es: ¿cómo puede dicha creencia estar garantizada? La respuesta que proporcionará y por la cual argumentará el autor (A.) consiste en afirmar que: "lo que garantiza esta creencia, como también la de haber recibido por revelación las verdades absolutas, es que estas no contravienen a ninguna obligación epistemológica que una ética de las creencias podría o desearía oponer" [p. 9]. Por lo tanto "las creencias religiosas no deben ser justificadas para ser legítimas” [p.9] sino que más bien "si el creyente no es intelectualmente vicioso, las creencias religiosas son garantizadas" [p. 10].

Roger Pouivet, Épistémologie des croyances religieuses, coll. «Philosophie et théologie », Éditions du Cerf, París, 2013, pp. 242. 
El libro se divide en tres partes (tres capítulos) donde el A. trata: “Capítulo I: La ética de las creencias religiosas” [pp. 25-90], “Capítulo II: Epistemología de la revelación” [pp. 93-154] y "Capítulo III: Realismo y anti-realismo teológicos” [pp. 157-215]. Dentro del primer Capítulo, R. P. comienza discutiendo la frase de William Clifford según la cual "creer algo basándose en una evidencia insuficiente es malo siempre, en cualquier lugar y para todo el mundo", lo que conduciría a pensar que las creencias religiosas son repugnantes tanto epistemológica como moralmente. El primer paso que seguirá el A. para construir una epistemología de las creencias religiosas es entonces rechazar el principio de Clifford, lo que le conduce a evitar el evidencialismo [pp. 35-39]. Frente a la crítica evidencialista, R. P. expone dos repuestas cristianas: la respuesta apologética [pp. 40-44] y la respuesta fideista. Para la primera el A. da como ejemplo Richard Swinburne, un excelente ejemplo de la apologética, la cual consiste en de defender una doctrina por medio de argumentos deductivos o inductivos. En cuanto a la segunda, esta rechaza el evidencialismo insistiendo en que la "fe religiosa es independiente de toda justificación epistémica” [p. 44] y que se trataría de "un asunto de confianza en Dios y de compromiso existencial hacía él” [p. 44]. Tanto la primera como la segunda, aunque respetables, no convienen según el A., a las respuestas que se deben adoptar cuando se trata de defender el derecho de creer. ¿Cuál es la razón? R. P. argumenta que aunque la fe contenga un elemento epistémico, no es equivalente a una creencia racional y por lo tanto no debe ser tratada como tal [pp. 47-52]. Esta puerta abierta, el A. defenderá la idea de que el hombre está predispuesto al conocimiento por su naturaleza misma, lo que garantizaría la legitimidad de sus creencias [pp. 59-63]; legitimidad también posible gracias a un precondicionalismo, este último entendido como "la tesis según la cual las creencias gracias a las cuales el examen de una teoría se efectúan -las creencias irresistibles- son correctas absolutamente” [p. 65], y el cual sería anti-fundacionalista, es decir que: "no disponemos de un conjunto de creencias justificadas formando una base indudable para nuestros edificios teóricos, ya que estas creencias supondrían otras” [p. 65]. 
Uno de los puntos claves del libro es el subcapítulo 8: "Creencias religiosas y epistemología de las virtudes” [pp.70-77], donde R. P. presenta una breve historia de la epistemología hasta llegar a la entrada de la filosofía moral de Elizabeth Anscombe; esta última, siendo importante para la epistemología de las virtudes. Este paso permitirá a R. P. de presentar una versión de la epistemología de las virtudes (versión adoptada por el autor), y la cual difiere, como lo confiesa el autor mismo, de la mayor parte de aquellos que se reclaman de dicha posición [p. 74]. En la versión defendida por R. P. (junto a L. Zagzebski, C. Hookway y J. Baehr y que se opone a la versión defendida por E. Sosa y J. Greco) las "virtudes no son facultades sino cualidades personales del creyente" [p. 74]. Por tanto la carga epistémica se desplaza de las creencias a las personas, o más bien a las cualidades de las personas. Es todo un giro de un proyecto epistemológico que se coloca en marcha. Este vendría a ser la tesis central de la epistemología de las virtudes: "el aspecto intelectual de una persona es decisivo" [p. 76]. En cuanto a qué son las virtudes epistémicas, el autor afirma que son: (1) “disposiciones adquiridas sobre la base de una capacidad natural”, que (2) "nos hacen destacar intelectualmente realizando aquello para lo que hemos sido hechos", que (3) "nos motivan a la búsqueda de la verdad” y que "nos aseguran el descubrimiento de la verdad" [p. 76].

La cuestión del testimonio tratada en el C. 9: "El testimonio cristiano" [pp. 77-91], es importante debido a que viene esclarecer el tema que se trata: las creencias religiosas. Para aceptar el testimonio cristiano, R. P. adoptará un particularismo epistémico, ya que "un particularista piensa que las normas se apoyan sobre las aptitudes naturales y sobre el sentido común" [p. 84]. El lector podrá apreciar que el A. va poco a poco construyendo un proyecto epistemológico de las creencias religiosas, en el cual "las virtudes epistémicas pueden jugar el papel de norma epistémica no evidencialista y no reduccionista dentro de la epistemología del testimonio” [p. 86]. Así lo que garantiza nuestras creencias, es: (1) que resultan de un proceso fiable que no insiste en las capacidades cognitivas (como lo hace Sosa y Greco), sino en las disposiciones intelectuales, (2) que el creyente es virtuoso [p. 87] y (3) de un situacionismo cognitivo -según el cual la persona tiene 
una capacidad a captar su situación cognitiva, es decir que el virtuoso logra adoptar la actitud correcta en su búsqueda de la verdad [p. 87-88]. El lector podría entonces preguntarse

El Capítulo II “Epistemología de la revelación” [pp. 93-157], analiza el conocimiento revelado en cuanto conocimiento. Es decir, trata "la posibilidad de un conocimiento gracias a la revelación o de un conocimiento revelado" (p. 94). El lector puede preguntarse si esta pregunta hace parte de la filosofía analítica de la religión, o si por lo contrario, la cuestión debería ser tratada dentro un marco teológico, es decir dentro de la teología analítica. Sin importar la respuesta de este interrogante, R. P. propone defender el conocimiento revelado (como conocimiento) gracias a la defensa de una epistemología de la gracia divina [p. 101-103], dejando así las puertas abiertas a una comprensión de la revelación como conocimiento compuesto por proposiciones inteligibles y de contenido universal [p. 115], y que puede ser garantizado por el papel epistémico que juega el Espíritu Santo [pp. 154-156]. Aunque este último punto pueda parecer confuso e incluso misterioso, es un punto en el cual ya había insistido Plantinga cuando hablaba de los efectos del pecado. R. P. se ve sin duda obligado a tratar este punto debido al tema que ha sido tratado en el capítulo: la revelación. Es aquí donde se puede apreciar que el trabajo del A se sitúa entre la filosofía analítica de la religión y la teología analítica.

El Capítulo III “Realismo y anti-realismo teológicos” [pp.157-216], es una defensa de la teoría de la verdad como correspondencia, después de una época anti-metafísica, que habría dejado en ruinas la teología moderna [pp. 160-164]. En este capítulo R. P. establecerá una interesante crítica contra algunos de los más importantes teólogos de nuestro tiempo, que habrían pasado de la metafísica al misticismo (como ya había sido señalado por Fergus Kerr). Dicho realismo teológico lo lleva a sostener que "hay una sola verdadera religión” [p. 164], una posición loable en una época relativista. El “diálogo estimulante entre el realista y el ficcionalista” [pp. 171-177] es sin duda recomendable para el lector para entender todo lo que está en juego. Cabe destacar las objeciones que R. P. dirigirá al ficcionalismo: el argumento antimentalista -que consistiría en rechazar el acceso a nuestros 
estados mentales, punto esencial de la teoría ficcionalista- [pp. 177-181], el argumento de la fe como consentimiento -consentimiento sobre hechos y no sobre nociones- [pp. 181-183], el argumento entre la diferencia entre creer y aceptar -que consiste en rechazar el tener como verdadera una proposición, sin creer que lo es- [p. 183], el argumento de la naturaleza de la disposición de la creencia y de la fe-evitar el fingir que Dios existe o simular que Dios existe, algo que iría en contra de un proceso de la creencia como disposición- [pp. 184-185] y el argumento de las limitaciones del fingimiento -que consiste en rechazar la acusación del ficcionalismo teológico según la cual dentro de la religión se finge- [pp. 185-186]. Así, adoptar un realismo teológico es el camino a seguir, y el único camino que deje abiertas las puertas a una teología seria y digna de su nombre. Un realismo teológico y por ende una teología seria debería evitar entonces el ficcionalismo [pp. 164-215] y el neowittgensteniano en teología y filosofía de la religión (particularmente la tesis de la religión como forma de vida) [pp. 186-215]. En efecto, el neowittgenstenianismo es una forma de ficcionalismo, según el cual lo realmente importante es la "práctica, el comportamiento, las experiencias, las formas de vida” [p. 187]. Por consiguiente, el neowittgenstenianismo rechaza el contenido proposicional asociados a las creencias religiosas. El lector puede preguntarse si el realismo teológico implica no seguir la tentación del pluralismo religioso [pp. 211-215]. La respuesta de R. P. parecería ser tangente: sí, el realismo teológico implica evitar el pluralismo religioso, ya que el "realismo pluralista es en realidad un anti-realismo” [p. 214]. Entonces, ¿cómo y por qué es preferible adoptar un realismo? El A. respondería que si se considera el dogma cristiano como un conjunto de verdades, sería simplemente ilógico de adoptar un ficcionalismo -ya que la Biblia sería una ficción, no una verdad-, un neowittgenstenianismo -ya que centrándose sobre la práctica, la verdad se deja de lado-, y un realismo pluralista -ya que sería incongruente con la revelación cristiana, y, rechazar el realismo pluralista viene a ser simplemente una consecuencia inevitable de considerar un realismo religioso "la tesis según la cual los dogmas cristianos son verdades” [p. 23]-. El realismo se convierte así en el fundamento “filosófico, racional y argumentativo, de las creencias cristianas" [p. 216]. 
El libro R. P. escrito de manera agradable y simple (sin contrarrestar calidad), posee un doble mérito: el primero consiste en proporcionar una obra que presenta el problema de las creencias religiosas, al mismo tiempo que se defiende una epistemología de las creencias religiosas (una epistemología de las virtudes), proporcionando de esta manera una excelente defensa del racionalismo del creyente. El segundo mérito que se desea atribuirle, es el de haber proporcionado un trabajo también de aspecto teológico (Cf. C. 2 y 3) que podría ser catalogado como haciendo parte de la reciente teología analítica.

\section{Referencias}

Clifford, W. K. 1999. The Ethics of Belief and Other Essays. New York: Prometheus Book.

Engel, P. 2006. Va savoir ! De la connaissance en général. París: Hermann.

Plantinga, A. 1993. Warrant: The Current Debate. Oxford: Oxford University Press. Pouivet, Roger. 2013. Épistémologie des croyances religieuses. París: Éditions du Cerf. Sosa, E. 2007. A Virtue Epistemology. Oxford: Clarendon Press.

Zagzebski, L. 1996. Virtues of the Mind. An Inquiry into the Nature of Virtue and the Ethical Foundations of Knowledge. Cambridge: Cambridge University Press. 